\title{
PENERAPAN MODEL QUANTUM TEACHING UNTUK MENINGKATKAN HASIL BELAJAR IPA TEMA PERISTIWA DALAM KEHIDUPAN PADA SISWA KELAS V SD NEGERI LEREPKEBUMEN TAHUN AJARAN 2019/2020
}

\author{
Anjar Wijiatmiko', Suhartono², Wahyudi ${ }^{3}$ \\ 1,2,3Universitas Sebelas Maret \\ anjar_wijiatmiko78@student.uns.ac.id
}

\section{Article History}

accepted 01/10/2020

\begin{abstract}
Application of Quantum Teaching Model to Improve Learning Outcomes of Science Theme of Events in Life in Class V Students of Lerepkebumen Elementary School in Academic Year 2019/2020. This study aims to improve the learning outcomes of natural science themes of events in life. This research is a collaborative classroom action research (CAR) carried out in three cycles. The subject of this research was the fifth grade students of Lerepkebumen Elementary School in 2019/2020 consisting of 39 students. Data collection techniques using observation, interviews, and tests. The validity of the data uses triangulation of techniques and sources. Quantitative data analysis uses descriptive statistics, while qualitative data analysis includes data reduction, data presentation, and drawing conclusions. The results of this study indicate that the Quantum Teaching model can improve the learning outcomes of Natural Sciences theme of events in life in the fifth grade students of SD Negeri Lerepkumen in the 2019/2020 school year. The average percentage of student learning outcomes in the first cycle was $85.89 \%$, the second cycle was $91.02 \%$, and the third cycle was $94.87 \%$. So, the Quantum Teaching model can be used as an alternative to improve science learning outcomes
\end{abstract}

Keywords: quantum teaching, learning outcomes, science

Abstrak: Penerapan Model Quantum Teaching untuk Meningkatkan Hasil Belajar IPA Tema Peristiwa dalam Kehidupan pada Siswa Kelas V SD Negeri Lerepkebumen Tahun Ajaran 2019/2020. Penelitian ini bertujuan untuk meningkatkan hasil belajar IPA tema peristiwa dalam kehidupan pada siswa kelas V SD Negeri Lerepkebumen tahun ajaran 2019/2020. Penelitian ini merupakan penelitian tindakan kelas (PTK) kolaboratif yang dilaksanakan dalam tiga siklus. Subjek penelitian ini adalah siswa kelas V SD Negeri Lerepkebumen tahun 2019/2020 yang terdiri dari 39 siswa. Teknik pengumpulan data menggunakan observasi, wawancara, dan tes. Validitas data menggunakan triangulasi teknik dan sumber. Analisis data kuantitatif menggunakan statistik deskriptif, sedangkan analisis data kualitatif meliputi reduksi data, penyajian data, dan penarikan kesimpulan. Hasil penelitian ini menunjukkan bahwa model Quantum Teaching dapat meningkatkan hasil belajar IPA tema peristiwa dalam kehidupan pada siswa kelas V SD Negeri Lerepkebumen tahun ajaran 2019/2020. Persentase ketuntasan hasil belajar siswa pada siklus I sebesar $85,89 \%$, siklus II sebesar $91,02 \%$, dan siklus III sebesar 94,87\%. Jadi, model Quantum Teaching dapat digunakan sebagai salah satu alternatif untuk meningkatkan hasil belajar IPA.

Kata kunci: quantum teaching, hasil belajar, IPA 


\section{PENDAHULUAN}

Pada abad 21 pelaksanaan pendidikan hendaknya mengikuti perkembangan zaman untuk mempersiapkan generasi yang terdidik dan berkualitas. Abad 21 menuntut setiap individu untuk memiliki suatu kecakapan atau keterampilan baik hard skill maupun soft skill yang mumpuni agar mampu berkiprah dalam kehidupan yang nyata. Oleh karena itu pendidikan hendaknya melaksanakan perbaikan kurikulum, mempersiapkan tenaga pendidik yang berkualitas, sampai dengan menyelenggarakan pembelajaran yang harus sesuai dengan pembentukan keterampilan abad 21. National Education Association (Redhana,2019: 2241) mengidentifikasi keterampilan abad ke21 meliputi berpikir kritis, kreativitas, komunikasi, dan kolaborasi. Keterampilanketerampilan tersebut dapat terbentuk melalui penyelenggaraan pendidikan yang efektif.

Penyelenggaraan pendidikan yang efektif salah satunya dengan menyelenggarakan proses pembelajaran yang efektif pula. Proses pembelajaran yang efektif terjadi ketika mampu menciptakan partisipasi aktif siswa di dalam kelas selama proses pembelajaran. Berkaitan dengan keterampilan abad 21, penyelenggaraan pembelajaran IPA di sekolah dasar hendaknya lebih menekankan pada keterampilan proses. Hal tersebut sejalan dengan pendapat Trianto (2011: 143) yang menjelaskan bahwa proses belajar mengajar IPA lebih ditekankan pada pendekatan keterampilan proses, hingga siswa dapat menemukan fakta-fakta, membangun konsep, teori-teori dan sikap ilmiah siswa itu sendiri. Hal itu sejalan dengan pendapat Semiawan (Isnanto, 2016: 2758) yang menyatakan bahwa dengan mengembangkan keterampilanketerampilan proses, siswa akan ampu menemukan dan mengembangkan sendiri fakta dan konsep serta menumbuhkan dan mengembangkan sikap dan nilai yang dituntut. Guru sebagai pengajar hendaknya mampu memilih model pembelajaran yang inovatif dan sesuai dengan materi pembelajaran yang akan disampaikan sehingga hasil belajar siswa memuaskan dan siswa aktif dalam pembelajaran.

Berdasarkan hasil observasi dan wawancara dan dengan guru kelas V SD Negeri Lerepkebumen pada tanggal 14 November 2018 tentang keaktifan siswa dalam mengikuti proses pembelajaran dan model pembelajaran yang biasa diterapkan mendapatkan hasil bahwa: (1) dalam proses pembelajaran guru masih dominan menggunakan metode ceramah dan penugasan, (2) guru belum menerapkan model pembelajaran yang inovatif, menyenangkan, dan meningkatkan motivasi belajar siswa, (3) siswa kurang aktif dan kurang antusias dalam mengikuti pembelajaran, Kondisi tersebut menyebabkan rendahnya hasil belajar IPA siswa kelas V SD Negeri Lerepkebumen Tahun Ajaran 2019/2020 pada Penilaian Tengah Semester (PTS). Rata-rata kelas pada muatan pelajaran IPA adalah sebesar 65,8 dari 39 siswa dengan Kriteria Ketuntasan Minimal (KKM) yaitu 65. Ketuntasan pada muatan pelajaran IPA siswa kelas V SD Negeri Lerepkebumen sebanyak 28 siswa dari 39 siswa, sedangkan yang belum mencapai KKM sebanyak 11 siswa dari 39 siswa.

Rendahnya hasil belajar IPA siswa kelas V SDN Lerepkebumen tahun ajaran 2019/2010 dikarenakan cara guru dalam penyampaian materi pelajaran IPA yang masih didominasi dengan ceramah, jarang menerapkan model pembelajaran dan media pembelajaran yang sesuai, siswa hanya menjadi objek pembelajaran. Materi yang luas menjadikan guru menggunakan sistem hafalan bagi siswa, padahal kemampuan menghafal setiap siswa itu berbeda-beda. Hal tersebut sering membuat siswa merasa bosan, cenderung pasif, kurang termotivasi, dan pada akhirnya kurang memperhatikan materi yang disampaikan guru dalam proses pembelajaran.

Berdasarkan uraian tersebut, apabila permasalahan itu dibiarkan maka akan berdampak buruk pada kegiatan pembelajaran IPA. Adapun pemecahan masalah ini adalah salah satunya penggunaan model Quantum Teaching untuk meningkatkan hasil belajar IPA. Model Quantum Teaching dipilih karena model ini menciptakan suasana belajar yang meriah, dengan segala nuansanya serta menyertakan segala kaitan 
antara interaksi, dan perbedaan yang memaksimalkan momen belajar sehingga diharapkan dapat meningkatkan hasil belajar pada mata pelajaran IPA.

Menurut Afacan dan Gurel (2019: 87) model Quantum Teaching adalah proses pembelajaran yang diwujudkan dengan memberikan latar belakang dan strategi untuk meningkatkan proses belajar-mengajar dan menjadikan proses ini lebih menyenangkan.. Pendapat tersebut sejalan dengan pendapat DePorter, Readon, dan Singer-Nourie (2011: 32) bahwa Quantum Teaching merupakan model yang menggubah suasana belajar menjadi meriah dengan semua nuansanya, menyertakan segala kaitan, interaksi, dan perbedaan yang memaksimalkan momen belajar. Guru nantinya mampu menciptakan suasana pembelajaran yang menyenangkan serta mampu memberikan pengetahuan yang lebih pada materi yang disampaikan guru. Menurut Mulyaningsih (2016: 4) penggunaan model Quantum Teaching dapat meningkatkan hasil belajar siswa yang masih rendah. Pendapat tersebut sejalan dengan Sampoerna, dkk (2020: 4) yang mengungkapkan bahwa model pembelajaran Quantum Teaching memusatkan perhatian pada pembentukan keterampilan akademis sehingga dapat meningkatkan hasil belajar.

Berdasarkan latar belakang masalah tersebut, peneliti tertarik melaksanakan penelitian pada siswa kelas V SD Negeri Lerepkebumen dengan harapan untuk mengetahui hasil penerapan model tersebut, maka peneliti melakukan penelitian kolaboratif dengan guru kelas V yang berjudul "Penerapan Model Quantum Teaching untuk Meningkatkan Hasil Belajar IPA Tema Peristiwa dalam Kehidupan pada Siswa Kelas V SD Negeri Lerepkebumen Tahun Ajaran 2019/2020". Tujuan penelitian ini yaitu : (1) mendeskripsikan langkah-langkah penerapan model Quantum Teaching untuk meningkatkan hasil belajar IPA tema peristiwa dalam kehidupan pada siswa kelas V, (2) meningkatkan hasil belajar IPA tema peristiwa dalam kehidupan melalui penerapan model Quantum Teaching pada siswa kelas V, (3) mendeskripsikan kendala dan solusi dalam menerapkan model Quantum Teaching untuk meningkatkan hasil belajar IPA tema peristiwa dalam kehidupan pada siswa kelas V.

\section{METODE PENELITIAN}

Penelitian ini merupakan penelitian tindakan kelas yang dilaksanakan secara kolaboratif antara peneliti dengan guru kelas. Subjek penelitian ini adalah seluruh siswa kelas V SD Negeri Lerepkebumen tahun ajaran 2019/2020 yang terdiri dari 39 siswa yang terdiri dari 21 siswa laki-laki dan 18 siswa perempuan.

Jenis data penelitian ini adalah data kualitatif berupa data tentang penerapan model Quantum Teaching dan data kuantitatif berupa data hasil belajar siswa pada muatan pelajaran IPA tema peristiwa dalam kehidupan. Sumber data dalam penelitian ini yaitu siswa kelas $\mathrm{V}$ dan guru kelas $\mathrm{V}$. Teknik pengumpulan data menggunakan observasi, wawancara, dan tes. Uji validitas data menggunakan triangulasi teknik dan sumber. Analisis data kuantitatif menggunakan statistik deskriptif, sedangkan analisis data kualitatif meliputi reduksi data, penyajian data, dan penarikan kesimpulan.

Aspek yang diukur dalam indikator kinerja penelitian ini adalah pelaksanaan langkah-langkah model Quantum Teaching dan ketuntasan hasil belajar IPA Tema Peristiwa dalam Kehidupan setelah menerapkan model Quantum Teaching dengan persentase yang ditargetkan sebesar $85 \%$. Penelitian ini menggunakan prosedur penelitian yaitu terdiri dari tahap perencanaan, pelaksanaan, pengamatan, dan refleksi.

\section{HASIL DAN PEMBAHASAN}

Penelitian ini dilaksanakan selama tiga siklus dengan menerapkan model Quantum Teaching menggunakan langkah-langkah : (1) tumbuhkan, (2) alami, (3) namai, (4) demonstrasikan, (5) ulangi, dan (6) rayakan. Langkah-langkah yang digunakan peneliti mengacu pada langkah model Quantum Teaching yang dikemukakan oleh DePorter, dkk. (2011: 39), Yahya (2017: 159-162), dan 
Fathurrohman (2015: 181-183) yang peneliti simpulkan menjadi langkah-langkah di atas.

Hasil pengamatan terhadap guru maupun siswa dalam penerapan metode inkuiri selalu mengalami peningkatan pada setiap siklus dan telah mencapai indikator pencapaian yang ditargetkan.

Tabel 1. Persentase Hasil Pengamatan terhadap Guru dan Siswa.

\begin{tabular}{|c|c|c|c|c|c|c|c|c|}
\hline \multirow{3}{*}{ Langkah } & \multicolumn{2}{|c|}{ Siklus I } & \multicolumn{2}{|c|}{ Siklus II } & \multicolumn{2}{|c|}{ Siklus III } & \multicolumn{2}{|c|}{ Rata-rata } \\
\hline & Guru & Siswa & Guru & Siswa & Guru & Siswa & Guru & Siswa \\
\hline & $\%$ & $\%$ & $\%$ & $\%$ & $\%$ & $\%$ & $\%$ & $\%$ \\
\hline Tumbuhkan & 80,20 & 79,68 & 90,10 & 88,02 & 88,54 & 87,50 & 86,28 & 85,06 \\
\hline Alami & 88,88 & 88,88 & 90,28 & 87,50 & 94,44 & 94,44 & 91,20 & 90,27 \\
\hline Namai & 86,97 & 85,41 & 90,62 & 88,02 & 93,75 & 91,67 & 90,44 & 83,36 \\
\hline Demonstrasi & 86,45 & 84,37 & 90,62 & 87,50 & 91,67 & 87,50 & 89,58 & 86,45 \\
\hline Ulangi & 89,58 & 89,58 & 93,75 & 89,58 & 95,83 & 91,67 & 93,05 & 90,27 \\
\hline Rayakan & 87,49 & 87,49 & 93,05 & 91,66 & 94,44 & 94,44 & 91,66 & 91,19 \\
\hline Rata-rata & 86,59 & 85,90 & 91,40 & 88,71 & 93,11 & 91,20 & 90,36 & 87,76 \\
\hline
\end{tabular}

Berdasarkan tabel 1, dapat dilihat bahwa pembelajaran pada siklus I persentase rata-rata ketepatan guru dalam menerapkan langkah-langkah model Quantum Teaching mencapai 86,59\% dan siswa 85,90\%. Persentase tersebut telah memenuhi indikator kinerja penelitian, sehingga penelitian dilanjutkan ke siklus II dengan harapan pelaksanaan pembelajaran menggunakan model Quantum Teaching lebih baik. Pembelajaran siklus II dilaksanakan berdasarkan hasil refleksi siklus I agar pelaksanaan pembelajaran pada siklus II menjadi lebih baik. Hasil pelaksanaan siklus II mengalami peningkatan dari siklus I yaitu guru mencapai $91,40 \%$ dan siswa $88,71 \%$. Persentase tersebut telah memenuhi indikator kinerja penelitian, sehingga penelitian dilanjutkan siklus selanjutnya dengan harapan pada siklus berikutnya menunjukan hasil yang benar-benar maksimal. Siklus III dilaksanakan berdasarkan hasil refleksi siklus II. persentase rata-rata ketepatan guru dalam menerapkan langkah-langkah model Quantum Teaching yaitu guru mencapai 93,11\% dan siswa 91,20\%.

Peningkatan hasil belajar siswa dapat dilihat setelah siswa mengikuti pembelajaran menggunakan model Quantum Teaching yang diukur melalui tes hasil belajar.

Tabel 2. Peningkatan Hasil Belajar IPA Tema Peristiwa dalam Kehidupan

\begin{tabular}{lccccc}
\hline \multirow{2}{*}{ Keterangan } & \multicolumn{2}{c}{ Siklus I } & \multicolumn{2}{c}{ Siklus II } & Siklus III \\
\cline { 2 - 6 } & Pert 1 & Pert 2 & Pert 1 & Pert 2 & Pert 1 \\
\hline Nilai Tertinggi & 100 & 100 & 100 & 100 & 100 \\
Nilai Terendah & 33 & 43 & 53 & 67 & 63 \\
Rata-rata & 78,97 & 82 & 83,10 & 84,97 & 85,79 \\
Tuntas & 33 & 34 & 35 & 36 & 37 \\
Persentase Tuntas (\%) & 84,61 & 87,17 & 89,74 & 92,30 & 94,87 \\
Belum Tuntas & 6 & 5 & 4 & 3 & 2 \\
Persentase Belum Tuntas (\%) & 15,3 & 12,8 & 10,25 & 7,69 & 5,2 \\
\hline
\end{tabular}

Berdasarkan tabel 2, dapat dilihat bahwa rata-rata hasil belajar siswa meningkat mulai dari siklus I sampai dengan siklus III. Rata-rata hasil belajar siswa pada siklus I 
pertemuan I sebesar 78,97; siklus I pertemuan 2 sebesar 82; siklus II pertemuan 1 sebesar 83,10; siklus II pertemuan 2sebesar 84,97; dan siklus III sebesar $85,79 \%$. Selain itu, persentase ketuntasan hasil belajar siswa juga selalu meningkat yaitu pada siklus I pertemuan 1 sebesar 84,61\%, siklus I pertemuan 2 sebesar $87,17 \%$, siklus II pertemuan 1 sebesar $89,74 \%$, siklus II pertemuan 2 sebesar $92,30 \%$, dan siklus III sebesar $94,87 \%$.

Penerapan model Quantum Teaching dapat meningkatkan hasil belajar IPA dikarenakan model pembelajaran tersebut menciptakan situasi lebih nyaman dan menyenangkan. hal tersebut membuktikan pendapat Shoimin (2014: 145-146) yang menyatakan bahwa kelebihan model Quantum Teaching adalah siswa dirangsang untuk aktif mengamati, menyesuaikan antara teori dengan kenyataan, dan dapat mencoba melakukannya sendiri. Hal tersebut akan berdampak baik pada hasil belajar siswa. Selain itu, Akbar dan J. A. Pramukantoro (Isnaini, Wigati, dan Diyah, 2016: 19) menyatakan bahwa model Quantum Teaching siswa diberi kesempatan untuk menunjukkan kemampuannya, akan memudahkan guru dalam mengontrol sejauh mana pemahaman siswa dalam belajar.

Hasil penelitian tersebut memperkuat penelitian sebelumnya yang dilakukan oleh Nurshabrina (2012: 70) yang menunjukkan bahwa dengan penerapan model Quantum Teaching sebagai upaya meningkatkan hasil belajar PKn materi globalisasi pada siswa kelas IV SDN Gumilir 05 Cilacap tahun ajaran 2011/2012. Penelitian sebelumnya juga dilakukan oleh Putri (2016: 102) yang menunjukkan bahwa penerapan model pembelajaran Quantum Teaching untuk meningkatkan hasil belajar IPA peserta didik kelas VC MIN 6 Bandar Lampung tahun ajaran 2015/2016.

Kendala pada penelitian ini ada 5 yaitu : (1) guru kesulitan dalam mengkondisikan siswa, (2) siswa tidak memperhatikan penjelasan guru dengan penuh perhatian, (3) siswa cenderung kurang aktif dalam penyampaian pendapat dan bertanya, (4) terdapat siswa yang membuat kegaduhan, dan (5) siswa kurang tenang saat menerima soal dan tidak mengecek kelengkapan soal.

Kendala wajar ditemui karena siswa belum terbiasa mengikuti pembelajaran dengan menggunakan model Quantum Teaching. Kendala ini disebabkan salah satunya merupakan kelemahan Quantum Teaching yang diungkapkan oleh Shoimin (2014: 146-147) yaitu: (1) model Quantum Teaching memerlukan kesiapan dan perencanaan yang matang di samping memerlukan waktu yang cukup panjang, (2) fasilitas seperti perlatan, tempat, dan biaya yang memadai tidak selalu tersedia dengan baik, (3) model Quantum Teaching terdapat perayaan untuk menghormati usaha seseorang siswa, baik berupa tepuk tangan, jentikan jari, nyanyian yang dapat mengganggu kelas lain, (4) banyak memakan waktu dalam hal persiapan, (5) model Quantum Teaching memerlukan keterampilan guru secara khusus karena tanpa ditunjang hal itu, proses pembelajaran tidak akan efektif, (6) model Quantum Teaching diperlukan ketelitian dan kesabaran agar harapan yang dilaksanakan dapat tercapai. Hal tersebut sejalan dengan pendapat Akbar dan J. A. Pramukantoro (Isnaini, Wigati, dan Diyah, 2016: 19) mengungkapkan kekurangan model Quantum Teaching yaitu: (1) model Quantum Teaching menuntut profesionalisme yang tinggi dari seorang guru, (2) banyaknya media dan fasilitas yang digunakan sehingga dinilai kurang ekonomis, (3) kesulitan yang dihadapi dalam menggunakan model quantum teaching akan terjadi dalam situasi dan kondisi belajar yang kurang kondusif sehingga menuntut penguasaan kelas yang baik.

Adapun solusi untuk mengatasi kendala di atas yaitu : (1) memberikan motivasi kepada siswa, (2) mengkondisikan siswa dengan baik, (3) memberikan contoh dan motivasi agar siswa lebih percaya diri, (4) menegur siswa dan melakukan ice breaking, dan (5) menegur siswa yang gaduh dan mengingatkan siswa untuk mengecek kelengkapan soal setelah soal dibagikan 


\section{SIMPULAN}

Berdasarkan hasil penelitian yang diperoleh, maka dapat disimpulkan bahwa:

1. Penerapan model Quantum Teaching untuk meningkatkan hasil belajar IPA tema peristiwa dalam kehidupan dilaksanakan menggunakan langkah-langkah: (a) tumbuhkan, (b) alami, (c) namai, (d) demonstrasikan, (e) ulangi, (f) dan rayakan.

2. Penerapan model Quantum Teaching dapat meningkatkan hasil belajar IPA tema peristiwa dalam kehidupan pada siswa kelas V SD Negeri Lerepkebumen tahun ajaran 2019/2020 dengan persentase ketuntasan hasil belajar siswa pada siklus I = $85,89 \%$, siklus $\mathrm{II}=91,02 \%$, dan siklus $\mathrm{III}=94,87 \%$.

3. Kendala dalam penerapan model Quantum Teaching untuk meningkatkan hasil belajar IPA tema peristiwa dalam kehidupan pada siswa kelas V SD Negeri Lerepkebumen tahun ajaran 2019/2020 ada 5 yaitu : (a) guru kesulitan dalam mengkondisikan siswa, (b) siswa tidak memperhatikan penjelasan guru dengan penuh perhatian, (c) siswa cenderung kurang aktif dalam penyampaian pendapat dan bertanya, (d) terdapat siswa yang membuat kegaduhan, dan (e) siswa kurang tenang saat menerima soal dan tidak mengecek kelengkapan soal. Adapun solusi untuk mengatasi kendala di atas yaitu : (a) memberikan motivasi kepada siswa, (b) mengkondisikan siswa dengan baik, (c) memberikan contoh dan motivasi agar siswa lebih percaya diri, (d) menegur siswa dan melakukan ice breaking, dan (e) menegur siswa yang gaduh dan mengingatkan siswa untuk mengecek kelengkapan soal setelah soal dibagikan.

Berkaitan dengan hasil penelitian yang telah dicapai, peneliti mengajukan saran sebagai berikut:

1. Bagi guru, hendaknya menjadi rekomendasi untuk diterapkan pada muatan pelajaran IPA di tema lain yang sesuai dengan langkah penerapannya sehingga dapat meningkatkan kemampuan mengingat, memahami, mengaplikasikan dan menganalisis dalam kegiatan pembelajaran.

2. Bagi siswa, hendaknya lebih bersemangat dan berani untuk mengemukakan pendapat dalam menanggapi kelompok lain ataupun bertanya mengenai hal yang belum dipahami agar mendapat hasil yang maksimal, (3) bagi sekolah, hendaknya menyediakan fasilitas, sarana dan prasarana serta mendukung guru untuk berinovasi dalam menggunakan model pembelajaran lain untuk meningkatkan pemahaman siswa.

3. Bagi pembaca/peneliti lain, hendaknya membuat pembelajaran yang lebih inovatif dan kreatif sesuai dengan perkembangan ilmu pengetahuan yang semakin maju. Salah satunya menerapkan model pembelajaran Quantum Teaching.

\section{DAFTAR PUSTAKA}

Afacan, O. \& Gurel, I. (2019). The Effect of Quantum Learning Model on Science Teacher Candidates' Self-Efficacy and Communication Skills (Versi Elektronik). Journal of Education and Training Studies,7 (4), 86-95. Diperoleh 8 Januari 2020 dari https://files.eric.ed.gov/fulltext/EJ1210750.pdf

DePorter,B., Reardon,M., \& Singer-Nourie,S. (2011). Quantum Teaching Mempraktikan Quantum learning di Ruang-Ruang Kelas. Bandung: Kaifa.

Isnaini, M., Wigati, I., Diyah, H. (2016). Pengaruh Model Pembelajaran Quantum Teaching dengan Langkah-langkah TANDUR terhadap Keterampilan Proses Belajar Siswa Materi Sel Kelas XI di SMA Muhammadiyah 1 Palembang (Versi Elektronik). Jurnal Bioilmi, 2 (1), 19. Diperoleh 8 Januari 2020, dari https. http://jurnal.radenfatah.ac.id/index. php/bioilmi/article/view/1155

Isnanto, H. (2016). Penerapan Pendekatan Alam Sekitar untuk Meningkatkan Keterampilan Proses IPA dan Sikap Ilmiah pada Siswa Kelas V di Sd Negeri Gedongtengen Yogyakarta (Versi Elektronik). Jurnal Penelitian Guru 
Sekolah Dasar, 29 (5), 2758-2764. Diperoleh 27 Desember 2019, dari http://journal.student.uny.ac.id/ojs/ojs/index. php/pgsd/article/view/4859

Mulyaningsih, E. (2016). Penerapan Model Quantum Teaching dalam Peningkatan Hasil Belajar IPA tentang Cuaca untuk Siswa Kelas III SD Negeri Poncowarno Tahun Ajaran 2013/2014. Skripsi Tidak Dipublikasikan, Universitas Sebelas Maret, Surakarta.

Nurshabrina, M. (2012). Penerapan Model Quantum Teaching Sebagai Upaya Meningkatkan Hasil Belajar PKN Materi Globalisasi pada Siswa Kelas IV SD Negeri Gumilir 05 Cilacap (Versi Elektronik) Doctoral dissertation, Universitas Negeri Semarang, 70. Diperoleh 15 juli 2020, dari https://lib.unnes.ac.id/19185/

Putri, M. D. (2016). Penerapan Model Pembelajaran Quantum Teaching untuk Meningkatkan Hasil Belajar IPA Peserta Didik Kelas VC Min 6 Bandar Lampung Tahun Ajaran 2015-2016 (Versi Elektronik). Doctoral dissertation, UIN Raden Intan Lampung, 102. Diperoleh 15 juli 2020, dari http://repository.radenintan.ac.id/594/

Redhana, I.W. (2019). Mengembangkan Keterampilan Abad Ke-21 dalam Pembelajaran Kimia (Versi Elektronik). Jurnal Inovasi Pendidikan Kimia,13 (1), 2239-2253. Diperoleh 16 November 2019, dari https://journal.unnes.ac.id/nju/index.php/JIPK/article/view/17824/8934

Sampoerna, R.M., Af'idah, N., Millah, N.D., \& Nursiana, P. (2020). Penerapan Model Pendidikan Quantum Learning melalui Pendekatan Kontekstual untuk Generasi Alpha Pada Anak Sekolah Dasar. Educational and Psychological Conferense in the 4.0 era Articles 8 (2020). Diperoleh 25 September 2020 dari https://press.umsida.ac.id/article/view

Shoimin, A. (2014). 68 Model Pembelajaran Inovatif dalam Kurikulum 2013, Yogyakarta: Ar-Ruzz Media

Trianto. (2011). Model Pembelajaran Terpadu Konsep, Strategi, dan Implementasi dalam Kurikulum Tingkat Satuan Pendidikan (KTSP). Jakarta: PT Bumi Aksara. 